\title{
CONCEITOS DE VALOR, INTERPRETAÇÃO, DIREITO E POLÍTICA: CRÍTICAS DE BERNARD WILLIAMS A RONALD DWORKIN
}

\author{
CONCEPTS OF VALUE, INTERPRETATION, LAW AND POLITICS: THE CRITICISMS OF \\ BERNARD WILLIAMS TO RONALD DWORKIN
}

Jacqueline de Souza Abreu ${ }^{1}$

SUMÁRIO: Introdução; 10 papel da história na análise de conceitos de valores; 2 Um modelo de decisão baseado no Direito Constitucional?; Considerações Finais; Referência das fontes citadas.

\section{RESUMO}

Ronald Dworkin tornou-se conhecido por contestar a inevitabilidade do conflito trágico entre valores morais e políticos como igualdade e liberdade. Subjacente à essa visão de Dworkin estão duas teses fundamentais de sua obra: sua teoria da interpretação e a tese da unidade de valor. Bernard Williams rejeitou diretamente a proposta de Dworkin, formulando críticas que se dirigem ao núcleo do pensamento dele. Este artigo explora duas críticas centrais de Williams: para ele, Dworkin não dá a importância devida à história na compreensão de conceitos de valores e supõe um padrão de interpretação desses valores típico do direito constitucional, que seria, entretanto, inadequado à política. Defendo que as críticas de Williams são superáveis: a história pode ser capaz de explicar origens de concepções rivais de valores como liberdade e igualdade, mas não faz parte das justificações delas; além disso, as concepções corretas de liberdade e igualdade não estão circunscritas ao que autoridades dizem que são, mas às melhores reconstruções desses valores. Assim, concluo que a visão de Dworkin sobre a inexistência do conflito inevitável sobrevive às críticas de Williams.

Palavras-chave: Ronald Dworkin; Bernard Williams; valores; interpretação; liberdade; igualdade.

\section{ABSTRACT}

Ronald Dworkin has become known for challenging the inevitability of a tragic conflict between equality and liberty as moral and political values. Underlying this view of Dworkin are two fundamental theses of his work: his theory of interpretation and the

\footnotetext{
${ }^{1}$ Doutoranda em Direito na Universidade de São Paulo, Departamento de Filosofia e Teoria Geral do Direito, São Paulo, Brasil. Mestra em Direito pela University of California, Berkeley (EUA) e pela LudwigMaximilians-Universität München (Alemanha). E-mail: jacqueline.abreu@usp.br.
} 
ABREU, Jacqueline de Souza. Conceitos de valor, interpretação, direito e política: críticas de Bernard Williams a Ronald Dworkin. Revista Eletrônica Direito e Política, Programa de Pós-Graduação Stricto Sensu em Ciência Jurídica da UNIVALI, Itajaí, v.13, n.2, $2^{\circ}$ quadrimestre de 2018. Disponível em: www.univali.br/direitoepolitica - ISSN 1980-7791

thesis of the unit of value. Bernard Williams directly rejected Dworkin's proposal, formulating criticisms that attack the core of Dworkin's thinking. This article explores two of these central criticisms: for Williams, Dworkin does not give due importance to history in understanding the concepts of values and assumes a standard of interpretation of these values typical of constitutional law, which is, however, unsuitable for politics. I argue that Williams' criticisms are surmountable: history may be able to explain the origins from rival conceptions of values such as liberty and equality, but it is not part of their justifications, which is what matters to see if there is a conflict between them as political values; furthermore, the correct conceptions of freedom and equality are not necessarily those endorsed by authorities, but those that best reconstruct the values in question. I conclude that Dworkin's view on conflict of values survives Williams' arguments.

Keywords: Ronald Dworkin; Bernard Williams; values; interpretation; liberty; equality

\section{INTRODUÇÃO}

O filósofo do direito Ronald Dworkin tornou-se conhecido por contestar a inevitabilidade do conflito trágico entre valores morais e políticos como igualdade e liberdade, argumentando que isso depende de como nós concebemos esses valores. ${ }^{2}$ Tal visão de "ouriço" 3 está na contramão daquela compartilhada por muitos teóricos contemporâneos do direito cujas premissas teóricas repousam no pluralismo de valores. Subjacente à visão de Dworkin estão duas teses fundamentais de sua obra: sua teoria da interpretação e a tese da unidade de valor.

Para Dworkin, na argumentação político-moral, conceitos de valores como liberdade e igualdade operam como conceitos interpretativos: estamos de acordo com o fato de que denominam virtudes e compartilhamos exemplos paradigmáticos de violação de liberdade ou igualdade, mas discutimos com frequência sobre a formulação mais

\footnotetext{
2 DWORKIN, Ronald. Do liberal values conflict?. In: R. DWORKIN; M. LILLA; R. SILVERS. The Legacy of Isaiah Berlin. New York: The New York Review of Books, 2001a, p. 91-104, p. 83. WALLUCHOW, W.; SCIARAFFA, S. The Legacy of Ronald Dworkin. Oxford: Oxford University Press, 2016.

${ }^{3}$ Ver DWORKIN, Ronald. Justice for Hedgehogs. Cambridge, MA: Harvard University Press, 2011; BERLIN, Isaiah. The hedgehog and the fox. London: Weidenfeld \& Nicolson, 1953; MACEDO JUNIOR, Ronaldo P. Do xadrez à cortesia: Dworkin e a Teoria do Direito Contemporânea. São Paulo: Saraiva, 2013.
} 
ABREU, Jacqueline de Souza. Conceitos de valor, interpretação, direito e política: críticas de Bernard Williams a Ronald Dworkin. Revista Eletrônica Direito e Política, Programa de Pós-Graduação Stricto Sensu em Ciência Jurídica da UNIVALI, Itajaí, v.13, n.2, $2^{\circ}$ quadrimestre de 2018. Disponível em: www.univali.br/direitoepolitica - ISSN 1980-7791

precisa desses conceitos e o que demandam em casos concretos. ${ }^{4}$ Apesar das disputas interpretativas e das aparentes contradições, por se assentarem em nossas convicções políticas mais profundas, Dworkin entende que é plausível que esses valores sejam interdependentes e se reforcem mutuamente. Atento a essa possibilidade e recusando-se a aceitar o pluralismo e o conflito de valores sem colocálos em questão, Dworkin explora as concepções que melhor articulariam esses valores como valores, reconstruídas a partir de nossas convicções, crenças e práticas que envolvem esses conceitos. Sua conclusão é de que as concepções dos conceitos de valores mais atraentes são capazes de nos levar à conclusão de que não só são coerentes entre si, como estão imbricados ou integrados.

É nesse contexto que Dworkin se engajou com o projeto de defender aquelas que seriam as melhores e corretas concepções de liberdade e igualdade. Na sua conhecida obra A Virtude Soberana (2000), afirmou que não há um direito geral à liberdade, mas direitos a liberdades que decorrem da melhor interpretação que se pode dar ao nosso comprometimento com a igual consideração e respeito. Também argumentou que a melhor concepção de igualdade distributiva é a igualdade de recursos, que se deixa delimitar contendo ao centro a noção de liberdade de escolha. Com isso pôde afirmar que liberdade e igualdade como valores políticos são não só compatíveis, mas integrados, ou seja, reforçam-se mutuamente. Ao mesmo tempo, suas interpretações sobre conceitos desses valores fortaleceram sua presunção forte a favor da unidade de valor.

O filósofo moral e político Bernard Williams, ainda pouco estudado no Brasil, rejeitou diretamente a proposta de Dworkin, formulando críticas que se dirigem ao núcleo central do seu pensamento. Em síntese, para Williams, Dworkin (i) não dá a importância devida à história na compreensão dos conceitos de valores; (ii) ignora a experiência do ressentimento na política; e (iii) supõe um padrão de interpretação

\footnotetext{
4 DWORKIN, Ronald. Do Values Conflict? A hedgehog's approach. Arizona Law Review, vol. 43, pp. 251-259, 2001b, p. 254-5.
} 
ABREU, Jacqueline de Souza. Conceitos de valor, interpretação, direito e política: críticas de Bernard Williams a Ronald Dworkin. Revista Eletrônica Direito e Política, Programa de Pós-Graduação Stricto Sensu em Ciência Jurídica da UNIVALI, Itajaí, v.13, n.2, $2^{\circ}$ quadrimestre de 2018. Disponível em: www.univali.br/direitoepolitica - ISSN 1980-7791

desses valores típico do direito constitucional, que é, entretanto, inadequado à política. Com suas críticas sofisticadas, Williams oferece uma perspectiva privilegiada para estudar pontos cruciais da teoria de Dworkin e suas eventuais fragilidades. Serve também de porta de entrada ao estudo do realismo político, tradição a que sua filosofia política se filia. ${ }^{5}$

Neste artigo, baseado em estudo sistemático das obras dos dois autores, exploro a primeira e a terceira críticas de Williams a Dworkin, discutidas nas seções 1 e 2 . A segunda foi explorada em outro trabalho. ${ }^{6}$ Nos mesmos tópicos, já apresento aquelas que podem ser as respostas de Dworkin às críticas que recebeu. A meu ver, a abordagem de Dworkin é capaz de superá-las. Por meio dessa estrutura, apresentamse as visões rivais de Bernard Williams e Ronald Dworkin sobre conceitos de valores, interpretação, direito e política.

\section{O PAPEL DA HISTÓRIA NA ANÁLISE DE CONCEITOS DE VALORES}

Dworkin defendeu que valores como igualdade e liberdade funcionam como conceitos interpretativos na argumentação político-moral. As pessoas disputam, acredita Dworkin, qual é o valor da igualdade e da liberdade, virtudes que endossamos e que exigimos que o Estado respeite. Contestam o significado desses conceitos, divergem sobre o que exigem e instituem. Apresentam em debates diferentes concepções desses conceitos. Em Do Liberal Values Conflict?, uma palestra que discutiu o legado do filósofo político pluralista Isaiah Berlin, assim afirmou Dworkin: "uma concepção

\footnotetext{
${ }^{5}$ CALCUTT, Daniel (ed.). Reading Bernard Williams. New York: Routledge, 2009; HALL, Edward. Realism and Liberalism in the Political Thought of Bernard Williams. Tese de Doutorado submetida ao Department of Government da London School of Economics and Political Science. 269 p. 2013. Disponível em: http://etheses.Ise.ac.uk/881/ . Acesso: 07.09.2017; JENKINS, Mark. Bernard Williams. Chesham: Acumen, 2006; KOOPMAN, Colin. Bernard Williams on Pluralism, Liberalism, and History. Theoretical and Applied Ethics, vol. 3, n.1, pp. 11-21, 2011; THOMAS, Alan (ed.). Bernard Williams. Cambridge: Cambridge University Press, 2007.

6 Ver ABREU, Jacqueline de Souza. O pluralismo de valores e sua importância política na obra de Bernard Williams. Teoria Jurídica Contemporânea, vol. 2, n.1, p. 6-38, 2017. Segundo Williams, a visão de Dworkin não é capaz de bem acomodar divergências políticas. No artigo, defendo que a teoria da interpretação de Dworkin não só dá conta de concepções distintas de valores políticas, como também é capaz de qualificar o debate.
} 
ABREU, Jacqueline de Souza. Conceitos de valor, interpretação, direito e política: críticas de Bernard Williams a Ronald Dworkin. Revista Eletrônica Direito e Política, Programa de Pós-Graduação Stricto Sensu em Ciência Jurídica da UNIVALI, Itajaí, v.13, n.2, $2^{\circ}$ quadrimestre de 2018. Disponível em: www.univali.br/direitoepolitica - ISSN 1980-7791

de liberdade é uma teoria interpretativa que almeja mostrar-nos por que é ruim quando a liberdade é negada". 7 Mostrar por que achamos ruim, por que achamos que perdemos algo de importante, implica justamente entender onde está o que valorizamos nela, qual o valor desse valor.

Dworkin afirma que "[acharmos] que a liberdade e a igualdade entram em conflito como ideais dependerá, indubitavelmente, de quais concepções de cada adotamos". ${ }^{8}$ Qual é a concepção que conta para verificar se há conflito? Como se pode dizer que ela diz o que igualdade e liberdade realmente são? Como avaliar uma concepção desses valores? No pensamento de Dworkin, não é possível fugir da interpretação. Segundo o autor, uma interpretação plausível de prática ou objeto interpretado deve passar por um teste de duas dimensões: deve ajustar-se (fit) à prática e mostrar seu point ou valor. ${ }^{9}$ É isto que permite dizer que uma interpretação é superior a outra: uma será tanto melhor quanto melhor adequar-se às práticas ou ao objeto e melhor justificar o valor a que serve. Esse ajuste (fit) não consiste em mera convergência empírica, nem são essas duas dimensões separáveis: a melhor interpretação é aquela que melhor se ajusta ao significado valorativo da prática a que ela se refere. ${ }^{10}$ As melhores concepções de liberdade e de igualdade serão aquelas, portanto, que melhor reconstruírem o significado do valor a que se referem esses conceitos, reconstruído a partir de nossas convicções, crenças e práticas que envolvem esses conceitos.

Estando diante das corretas - ou, pelo menos, as melhores disponíveis - concepções

\footnotetext{
7 DWORKIN, Ronald. Do liberal values conflict?. p. 89, tradução minha.

8 DWORKIN, Ronald. Sovereign Virtue: The Theory and Practice of Equality. Cambridge, MA: Harvard University Press, 2000, p. 126.

${ }^{9}$ DWORKIN, Ronald. Uma questão de princípio. 2a Ed. São Paulo: Martins Fontes, 2005, p. 239.

10 Sobre o fit valorativo de Dworkin, alvo de muitas incompreensões sobre sua obra, cf. MACEDO JUNIOR, Ronaldo P. Do xadrez à cortesia: Dworkin e a Teoria do Direito Contemporânea, pp. 199-234.
} 
ABREU, Jacqueline de Souza. Conceitos de valor, interpretação, direito e política: críticas de Bernard Williams a Ronald Dworkin. Revista Eletrônica Direito e Política, Programa de Pós-Graduação Stricto Sensu em Ciência Jurídica da UNIVALI, Itajaí, v.13, n.2, $2^{\circ}$ quadrimestre de 2018. Disponível em: www.univali.br/direitoepolitica - ISSN 1980-7791

de valores como liberdade e igualdade, é que será possível dizer se existe um conflito conceitual inevitável entre esses valores. ${ }^{11}$ Há de ser assim porque são as melhores concepções as que revelam esses valores políticos como os valores políticos que são, a natureza e a essência deles. Para Dworkin, são elas que constituem as concepções a serem levadas em conta para a verificação do conflito. São elas as que passam no teste metodológico interpretativo, que melhor revelam o que importa nestes valores a partir de nossas conviç̧ões sobre eles. As concepções de Dworkin, se estiverem certas, mostram não só que valores como liberdade e igualdade são conciliáveis, como também que estão integrados e se reforçam mutuamente.

Tudo até aqui foi escrito sem se falar em história e do papel que ela tem na compreensão que temos do que seja liberdade e igualdade. Isto é algo preocupante, para Williams. Para entender os conceitos que usamos, precisamos da história, segundo ele. A filosofia, que em grande parte se dedica a compreender nossos conceitos, para compreender o que nós somos, precisa da história. ${ }^{12}$ É o que Williams defende em Why philosophy needs history, por exemplo. Ele afirma que apesar de vários filósofos se dedicarem à história da filosofia, muitos negligenciam a história dos conceitos que a filosofia quer entender: não compreendemos nossos ideais políticos, por exemplo. ${ }^{13}$ Williams continua:

Há uma história por trás desses conceitos: a história de como as pessoas vieram a pensar assim. No caso de algumas ideias, como de igualdade política ou legitimidade democrática, ou virtudes de sinceridade e honestidade, a história será densa e distinta à nossa própria cultura, quando contrastada com culturas de

${ }^{11}$ DWORKIN, Ronald. Do Values Conflict? A hedgehog's approach. p. 256.

12 Williams escreveu dois artigos especialmente sobre a importância da história para a filosofia "Why Philosophy needs History", publicado em 2002 pela London Review of Books e republicado em Essays and Reviews 1959-2002 (2014, pp. 405-12), obra que reúne seus ensaios, e "Philosophy as a Humanistic Discipline", publicado originalmente no livro Philosophy 75 e republicado em livro que recebeu o mesmo nome do artigo (2006, pp. 180-199). Além destes artigos, dedicou-se ao tema no livro Truth and Truthfulness (2002).

13 WILLIAMS, Bernard. Essays and Reviews: 1959-2002. Princeton: Princeton University Press, 2014, p. 405. 
ABREU, Jacqueline de Souza. Conceitos de valor, interpretação, direito e política: críticas de Bernard Williams a Ronald Dworkin. Revista Eletrônica Direito e Política, Programa de Pós-Graduação Stricto Sensu em Ciência Jurídica da UNIVALI, Itajaí, v.13, n.2, $2^{\circ}$ quadrimestre de 2018. Disponível em: www.univali.br/direitoepolitica - ISSN 1980-7791

tempos passados e também, talvez, de outras sociedades existentes. ${ }^{14}$

A assunção de que a investigação filosófica não precisa da história, bastando a reflexão sobre os conceitos está, portanto, errada, para Williams. ${ }^{15}$ Esta visão negligencia que, para entender questões e disputas que envolvem certos conceitos, precisamos da história que estão por trás deles. Ele concede, entretanto, que não é em todos os casos que a história de um conceito é relevante, apesar de ela existir. A história do conceito de "átomo", por exemplo, pouco contribui para o que nos perturba sobre esse conceito agora, uma vez que a ideia moderna de átomo não é mais a mesma de quando ela primeiro surgiu. Este é também um caso em que não importa se é o mesmo conceito que é empregado em diferentes culturas e sociedades. ${ }^{16}$ Williams quer dizer: para se estudar, fazer ciência sobre átomos, não é preciso conhecer a história deste conceito. ${ }^{17}$ Quando se fala em ideais políticos, por outro lado, a história é importante:

Existem, entretanto, algumas ocasiões muito importantes em que nós precisamos dizer tanto que há uma variação histórica entre uma ideia ou conceito usado por dois diferentes grupos e que elas são em algum sentido formas variadas do mesmo conceito. Nós precisamos dizer isso particularmente para conceitos de valor como liberdade [freedom] e justiça, em que pode haver conflitos significantes de interpretações do valor em diferentes tempos e em diferentes grupos: entre liberdade [freedom] como uma vida disciplinada em uma república independente e liberdade [freedom] na $8^{\text {a }}$ Avenida. Tentando entender os problemas que nós temos com a ideia de liberdade [freedom], precisamos descrever e entender essas diferenças,

\footnotetext{
14 WILLIAMS, Bernard. Essays and Reviews: 1959-2002. p. 406, tradução minha.

15 WILLIAMS, Bernard. Essays and Reviews: 1959-2002. p. 406.

16 WILLIAMS, Bernard. Essays and Reviews: 1959-2002. p. 406.
}

\footnotetext{
17 Em Philosophy as a Humanistic Discipline, Williams distingue conceitos éticos e políticos de conceitos científicos. Acerca dos segundos, afirma o seguinte: "Of course, scientific concepts have a history: but on the standard view, though the history of physics may be interesting, it has no effect on the understanding of physics itself. It is merely part of the history of discovery." (p. 189).
} 
ABREU, Jacqueline de Souza. Conceitos de valor, interpretação, direito e política: críticas de Bernard Williams a Ronald Dworkin. Revista Eletrônica Direito e Política, Programa de Pós-Graduação Stricto Sensu em Ciência Jurídica da UNIVALI, Itajaí, v.13, n.2, $2^{\circ}$ quadrimestre de 2018. Disponível em: www.univali.br/direitoepolitica - ISSN 1980-7791

precisamos dizer que em algum sentido elas representam diferentes interpretações da mesma coisa: simplesmente dar diferentes nomes a esses valores em conflito iria perder de vista a questão [point] do conflito. ${ }^{18}$

Esta última afirmação de Williams nos leva ao ponto que quer fazer: liberdade, igualdade, justiça "têm história". ${ }^{19}$ Williams afirmou que as "preocupações-matriz a que esses valores se referem são elaboradas e aplicadas historicamente em uma cultura ou sociedade" e defendeu uma determinada "estrutura de conceitos de valores". A elaboração desse esquema parte de duas considerações. A primeira (i) é a de que cada conceito se conecta com algum tipo distinto de "preocupação". ${ }^{20}$ Liberdade e igualdade são valores distintos, não são diferentes nomes de um mesmo conceito, ressalta Williams. A eles estão relacionadas preocupações distintas. Em relação à liberdade, a preocupação talvez seja não estar no poder de outrem. A da justiça ${ }^{21}$, dar a cada um o que é devido. Williams chama esta característica de "matriz" (matrix) ou "esquema básico de preocupação" (basic schema of concern) do conceito. A segunda consideração (ii) é a de que a matriz de um conceito de valor é demasiado nua e esquemática e, por isso, indeterminada: precisa de elaboração social, histórica e cultural, o que de fato esses conceitos já receberam de formas distintas em diferentes sociedades e culturas. ${ }^{22}$ Ele pretende assim pontuar que os conceitos requerem história. Explica: os conceitos carregam avaliações sobre o que as pessoas valorizam, sendo plausível dizer, por exemplo, que pessoas universalmente

\footnotetext{
18 WILLIAMS, Bernard. Essays and Reviews: 1959-2002. p. 406-7, tradução minha.

19 WILLIAMS, Bernard. Liberalism and Loss. In: DWORKIN, Ronald; LILLA, Mark; SILVERS, Robert. The Legacy of Isaiah Berlin. New York, The New York Review of Books, p. 91-104, 2001a, p. 91.

20 WILLIAMS, Bernard. Liberalism and Loss. p. 92.

${ }^{21}$ Williams prefere contrastar, ao invés de liberdade e igualdade, na palestra, liberdade e justiça. "The first thing we have two bear in mind is that liberty and equality - lets say, rather more broadly, liberty and justice - are two different values" (WILLIAMS, Bernard. Liberalism and Loss. p. 92). A sua opção por falar em justiça aqui, "de forma mais abrangente", não será um problema, contudo, uma vez que parece se referir a alguma versão de igualdade.
}

22 WILLIAMS, Bernard. Liberalism and Loss. p. 93. 
ABREU, Jacqueline de Souza. Conceitos de valor, interpretação, direito e política: críticas de Bernard Williams a Ronald Dworkin. Revista Eletrônica Direito e Política, Programa de Pós-Graduação Stricto Sensu em Ciência Jurídica da UNIVALI, Itajaí, v.13, n.2, $2^{\circ}$ quadrimestre de 2018. Disponível em: www.univali.br/direitoepolitica - ISSN 1980-7791

ressentem ser arbitrariamente destratadas (pushed around) por outras pessoas. 0 que conta como "arbitrário" será, contudo, uma questão de elaboração histórica e social que fará o valor em questão ser localmente inteligível. É essa a forma como os conceitos precisam ser compreendidos, como continua na afirmação seguinte ao trecho citado acima: "é útil pensar em termos de um núcleo comum compartilhado por valores em conflito, que é desenvolvida e expressada por eles em diferentes formas" (Williams, 2014, p. 407, tradução minha).

Essa abordagem de Williams marca uma divergência metodológica importante entre ele e Ronald Dworkin a ser pontuada neste trabalho. Os autores parecem não compartilhar uma mesma "teoria dos conceitos" e isso tem repercussões não só nas suas visões sobre a potencialidade de conflito entre valores como liberdade e igualdade, e consequente incompatibilidade entre tais conceitos, como também, de forma mais abrangente, em suas defesas do pluralismo de valores e da unidade de valor.

Para Williams, dado que valores possuem uma estrutura conceitual básica - um esquema de preocupação e uma elaboração histórica - , e esta seria a forma adequada de compreender esses conceitos, a conclusão que segue é a de que "esses valores não podem ser redirecionados nominalmente, redefinindo-se uma palavra". ${ }^{23}$ É por isso que Williams vai criticar aqueles que pretendem "sistematizar" valores harmonicamente, de forma que não haja conflitos. É o que diz em Liberalism and Loss, sua palestra na mesma conferência sobre o legado de Isaiah Berlin mencionada anteriormente:

Suponha que alguém produza uma definição ou compreensão da liberdade [liberty], e uma definição ou compreensão de justiça, e então por razões sistemáticas tenta fazer os dois valores ajustarem-se entre si, no sentido forte de que eles estarão imunes a certos tipos de conflito de princípio. Ele não só alega que isso seria teoricamente mais organizado e mais simples: reduziria, ele diz, conflito político e jurídico e faria mais sentido de nossa

23 WILLIAMS, Bernard. Liberalism and Loss. p. 94. 
ABREU, Jacqueline de Souza. Conceitos de valor, interpretação, direito e política: críticas de Bernard Williams a Ronald Dworkin. Revista Eletrônica Direito e Política, Programa de Pós-Graduação Stricto Sensu em Ciência Jurídica da UNIVALI, Itajaí, v.13, n.2, $2^{\circ}$ quadrimestre de 2018. Disponível em: www.univali.br/direitoepolitica - ISSN 1980-7791

situação se definirmos os termos dessa forma. Ele pode mesmo ter alguma razão para isso. Mas a questão significativa é que você não pode necessariamente fazer com que as preocupações básicas que vão com esses valores sigam propostas sistemáticas, porque a preocupação com o valor é dirigida à coisa que foi selecionada na matriz, que é por sua vez mediada pela história. ${ }^{24}$

Williams parece ter Dworkin em mente quando imaginou esse "alguém" com um interesse sistematizador dos conceitos. O trecho é de uma palestra em que Dworkin tinha acabado de apresentar seus argumentos contra o conflito inevitável de Berlin, afirmando que a existência do conflito depende da forma como concebemos os valores igualdade e liberdade e é bastante provável que Williams já conhecia as defesas da integração da liberdade com a igualdade de recursos proposta por Dworkin. ${ }^{25} \mathrm{~A}$ crítica que ele faz aqui é, então, atribuir a Dworkin um interesse em produzir coerência entre valores que, assim, negligencia o papel que a história tem na estrutura do que eles são.

Antes de investigarmos essa divergência sobre o papel da história, cumpre-me apresentar algumas palavras sobre a visão que Williams parece ter de Dworkin. A meu ver, essa pretensão "sistematizadora-coerentista" pela produção de definições ajustadas que Williams parece atribuir a Dworkin não é exatamente fiel à sua proposta. De fato, Dworkin fala em sua palestra Do Liberal Values Conflict? que a existência de um conflito inevitável trágico entre liberdade e igualdade "depende do que queremos dizer com liberdade e igualdade"26, o que pode facilmente dar lugar a

\footnotetext{
${ }^{24}$ WILLIAMS, Bernard. Liberalism and Loss. p. 94, tradução minha.

25 O texto de Dworkin "Equality of Resources: The Place of Liberty (Part III)" de 1987 (republicado em DWORKIN, Ronald. Sovereign Virtue: The Theory and Practice of Equality. p. 120-183) foi objeto de crítica direta da parte de Williams no artigo Conflicts of Liberty and Equality (2005, pp. 115-27). Falei em ser "bastante provável", uma vez que o artigo de Williams foi publicado postumamente em 2005, enquanto a palestra ocorreu em 1997. Como já indiquei anteriormente, Dworkin e Williams se influenciaram academicamente de forma muito rica, o que me permite supor que Williams conhecia tal artigo de Dworkin desde o tempo em que foi originalmente publicado.

26 "Do liberty and equality, now considered as abstract values, conflict in some way that explains why a political community might find itself not merely uncertain about what to do but certain that it must do
} 
ABREU, Jacqueline de Souza. Conceitos de valor, interpretação, direito e política: críticas de Bernard Williams a Ronald Dworkin. Revista Eletrônica Direito e Política, Programa de Pós-Graduação Stricto Sensu em Ciência Jurídica da UNIVALI, Itajaí, v.13, n.2, $2^{\circ}$ quadrimestre de 2018. Disponível em: www.univali.br/direitoepolitica - ISSN 1980-7791

entender que o exercício que Dworkin estava fazendo era o de simplesmente mudar as definições destes conceitos. Há também outros textos em que a explicação de seu método interpretativo permite ser confundida dessa forma ${ }^{27}$ e, na própria conferência sobre o legado de Berlin, ela teve de ser "esclarecida" quando do debate ${ }^{28}$ sobre as palestras de Dworkin e Williams.

O ponto de Dworkin é o de que não podemos supor, por default, que liberdade e igualdade estão em conflito. Se as concepções desses valores forem as de que "liberdade é ausência de restrição" e igualdade é "igual riqueza para todos", é claro que haverá conflito. Nós não temos nenhuma razão, contudo, para dizer que essas são as concepções que revelam como nos engajamos com esses valores e por que eles são importantes para nós. Essas são concepções que se mostram pouco

wrong whatever it does? That depends on what we mean by liberty and by equality: it depends on how we conceive these abstract values." DWORKIN, Ronald. Do liberal values conflict?. p. 83.

27 Em Do values conflict? A hedgehog's approach, em que defende a mesma tese apresentada na palestra, Dworkin afirma que "of course we can define the various political virtues in such a way that conflict is inevitable" (p. 253), para em seguida apresentar as concepções que vimos que ele atribui a Berlin. A seguir, afirma: "But why should we define them that way? Here are two other definitions I want two put before you" (p. 253), de forma a parecer que vai oferecer definições alternativas com o fim de evitar o conflito. A leitura atenta deste mesmo artigo, principalmente de um leitor familiarizado com a obra de Dworkin, é capaz de evitar incompreensões, uma vez que mais para frente no mesmo artigo ele afirma que liberdade e igualdade são conceitos interpretativos e explica, em linhas gerais, o que isso quer dizer. Contudo, não é difícil compreender por que Williams pensou que Dworkin estava tentando "brincar" com conceitos ou mesmo tentar "defini-los" fixamente.

28 O filósofo Richard Wollheim, também participante da conferência sobre o legado de Berlin, após afirmar na Discussion (DWORKIN, Ronald; LILLA, Mark; SILVERS, Robert (eds.). The Legacy of Isaiah Berlin. New York: The New York Review of Books, 2001, p. 121-39) que Isaiah Berlin estava mais preocupado em sua obra com conflitos intrapessoais (e não com interpessoais, como os trabalhados nas palestras de Dworkin e Williams), afirmou que: "I think that if you take this other kind of conflict [intrapersonal conflict], the kind of gerrymandering with values that Ronald Dworkin advocates is less plausible" (p. 136, grifo meu). ("Gerrymandering" se refere à prática de manipular limites de distritos eleitorais para favorecer um partido ou uma classe.) Ao que Dworkin respondeu: "I want to respond to your use of 'gerrymandering', however, because that suggests, as several comments have, that I am twisting the meaning of a perfectly natural and clear concept - liberty - just to achieve a desirable political goal. But that is what I deny. The alternative to gerrymandering electoral districts is to accept compact, naturally shaped districts. But we have no 'natural' alternative in political philosophy." (p. 137) Dworkin volta a distinguir sua proposta dessa má-compreensão em DWORKIN, Ronald. Justice for Hedgehogs. Cambridge, MA: Harvard University Press, 2011, p. 5: aí fala da "cama de Procusto", o qual colocava seus convidados em sua cama esticando-os e podando-os até que coubessem. Não é isso que Dworkin está fazendo, pelo contrário: pretende desenvolver concepções integradas de virtudes políticas que pareçam corretas em si mesmas. 
ABREU, Jacqueline de Souza. Conceitos de valor, interpretação, direito e política: críticas de Bernard Williams a Ronald Dworkin. Revista Eletrônica Direito e Política, Programa de Pós-Graduação Stricto Sensu em Ciência Jurídica da UNIVALI, Itajaí, v.13, n.2, $2^{\circ}$ quadrimestre de 2018. Disponível em: www.univali.br/direitoepolitica - ISSN 1980-7791

atraentes, aliás, nesse exercício sobre o que valorizamos. Só podemos concluir que há um conflito inevitável entre liberdade e igualdade se, diante das melhores concepções defendidas destes conceitos, elas se mostrarem em conflito ${ }^{29}$. Deve ser assim porque são elas as corretas concepções do que esses valores são. Dworkin não está procurando forçar definições ajustadas.

Esse ponto não altera, contudo, o argumento de Williams sobre a importância da história para a compreensão dos conceitos e que precisa ser analisado. Dworkin teve a oportunidade de explicar, na conferência, por que não acredita que a história tenha papel central na questão posta acerca da compreensão de conceitos de valores políticos. Isto é o que diz, dirigindo-se diretamente a Williams:

Eu quero comentar, finalmente, o papel que outros palestrantes atribuíram à história. Nós temos que tomar cuidado para distinguir três questões. $O$ que as pessoas discutiram e sobre o que se dividiram no passado? Como as pessoas podem ser trazidas a discutir e a se dividir menos hoje? Quando elas discutem e se dividem, um lado está certo e, se sim, qual lado? Berlin tratou dessas três questões, mas uma de suas maiores contribuições foi diferenciá-las, e suas observações sobre o pluralismo de valores se dirigiram à terceira. De que forma a história nos ajuda a esclarecer essa questão? Por exemplo: quando é certo que pessoas estejam sob o poder das outras e quando não? Bernard diz que a história nos mostra que as pessoas têm um grande desejo de não estar sob poder de ninguém e que nossa preocupação com a liberdade [liberty] decorre dessa preocupação. Mas ele também diz que às vezes não é uma violação da liberdade [liberty] quando algumas pessoas estão sob o poder de outras. O assassino deve estar sob nosso poder, diz Bernard, e seria ingênuo achar que isso é uma invasão da liberdade [liberty] dele. // Então precisamos de algo mais do que

\footnotetext{
29 Dworkin volta a esclarecer este ponto na Discussion da palestra: "I've been concentrating so far on a negative claim about that process: that we have been no reason for thinking, in advance, that when we construct these conceptions with that aim in view [finding the most attractive conception] we will encounter conflicts of the kind Berlin declared [...]" (Dworkin em DWORKIN, Ronald; LILLA, Mark; SILVERS, Robert (eds.). The Legacy of Isaiah Berlin. p. 127). Dworkin também defende o argumento positivo de que a 'integridade' entre valores é um valor. Não me concentrei nesta parte do argumento, por ora, uma vez que não é necessária para esclarecer a ideia.
} 
ABREU, Jacqueline de Souza. Conceitos de valor, interpretação, direito e política: críticas de Bernard Williams a Ronald Dworkin. Revista Eletrônica Direito e Política, Programa de Pós-Graduação Stricto Sensu em Ciência Jurídica da UNIVALI, Itajaí, v.13, n.2, $2^{\circ}$ quadrimestre de 2018. Disponível em: www.univali.br/direitoepolitica - ISSN 1980-7791

história. Precisamos confrontar a questão essencialmente moral de como construímos o ideal de liberdade [liberty]. ${ }^{30}$

Dworkin distingue, portanto, a explicação sobre por que temos as convicções e intuições que temos sobre valores como liberdade e igualdade e as causas do por que nós os valorizamos, elementos que podem levar a distintas visões em diferentes sociedades e entre diferentes pessoas, do exercício necessário para responder à pergunta "há alguém certo em suas concepções sobre esses valores e, se sim, quem?". Assim, Dworkin quer chamar atenção que a explicação das concepções defendidas por diferentes pessoas e povos, que gera tanta controvérsia, precisa, sim, da história para ser entendida. A história, contudo, não tem nada a oferecer quando queremos responder quem defende as melhores concepções desses conceitos de valores, o que depende da justificação que é dada a elas, e que é relevante para sabermos se há conflito entre valores políticos de forma inevitável e trágica.

Dworkin faz essa distinção entre explicação e justificação de um conceito de forma mais clara em Justice for Hedgehogs ${ }^{31}$, mas ela já havia sido feita em Law's Empire, apesar de então ainda não nomear a distinção dessa maneira. ${ }^{32}$ Com ela, distingue as ideias de origem causal de um conceito e das conviç̧ões que temos que o envolvem do argumento, teoria e razões que o sustentam.

O simples fato de que minhas conviç̧ões morais seriam muito diferentes se eu tivesse me educado de maneira diferente, ou em uma época muito diferente, não mostra em si, nenhum defeito na cultura, na formação e nos processos de reflexão e observação que finalmente produziram as conviç̧ões que agora tenho. [...] Sei que minhas opiniões seriam diferentes se eu tivesse vivido numa época muito diferente. Mas acho que minhas conviç̧ões são melhores, e também diferentes, e nenhuma explicação causal

30 Dworkin em DWORKIN, Ronald; LILLA, Mark; SILVERS, Robert (eds.). The Legacy of Isaiah Berlin. p. 123-4, tradução minha.

${ }^{31}$ DWORKIN, Ronald. Justice for Hedgehogs. p. 46-8; 79-80.

32 DWORKIN, Ronald. Law's Empire. Cambridge, MA: Harvard University Press, 1986, p. 426-8; DWORKIN, Ronald. 0 império do direito. 2a Ed. São Paulo: Martins Fontes, 2007, p. 104-5. 
pode obrigar-me a abandonar esse ponto de vista, ainda que um argumento moral certamente possa fazê-lo. ${ }^{33}$

Sendo assim, o fato de que as convicções que sustentamos acerca do que valores como igualdade e liberdade são, do que requerem e protegem possam estar relacionadas com a situação histórica em que vivemos não muda o fato de que temos de defender nossas concepções substantivamente. Somente um argumento moral acerca do valor político da liberdade e da igualdade que pretenda melhor revelar esse valor é que exprime o que são esses valores políticos.

Em Why philosophy needs history, Williams mostra-se ciente dessa defesa e as suas considerações acerca do conteúdo histórico de conceitos de valor ganha implicações céticas, já que Dworkin acredita ser possível defender concepções corretas de conceitos de valores:

Alguns filósofos negam que qualquer crônica histórica poderia justificar (ou falhar em justificar [vindicate]) nossos valores. Eles veem uma tal ideia como um exemplo da "falácia genética": são razões ou justificações que contam, não origens. Mas isso ignora a possibilidade de o valor em questão poder entender a si mesmo, apresentar-se a si mesmo e reclamar autoridade em termos que uma história genealógica pode solapar. ${ }^{34}$

Ele sustenta esse seu argumento fazendo a seguinte pergunta a título exemplificador: se valores liberais constituem a ordem moral verdadeira do mundo, que emergiu da razão e representa uma realização cognitiva, como alguns filósofos liberais têm defendido para justificar suas teorias do liberalismo, por que esses valores somente se revelaram em certos lugares e apenas nos últimos três séculos ${ }^{35} \mathrm{O}$ seu ponto aqui é o de que a história pode desqualificar as razões que sustentam um argumento moral. Assim sendo, ela não influenciaria apenas a explicação acerca de por que

\footnotetext{
33 DWORKIN, Ronald. O império do direito. p. 105.

34 WILLIAMS, Bernard. Essays and Reviews: 1959-2002. p. 410, tradução minha.

35 WILLIAMS, Bernard. Essays and Reviews: 1959-2002. p. 410.
} 
ABREU, Jacqueline de Souza. Conceitos de valor, interpretação, direito e política: críticas de Bernard Williams a Ronald Dworkin. Revista Eletrônica Direito e Política, Programa de Pós-Graduação Stricto Sensu em Ciência Jurídica da UNIVALI, Itajaí, v.13, n.2, $2^{\circ}$ quadrimestre de 2018. Disponível em: www.univali.br/direitoepolitica - ISSN 1980-7791

temos os conceitos de valor que temos, como quer Dworkin, mas atingiria também a própria justificação dada a eles que se pretenda ser a melhor, correta.

A objeção de Williams neste ponto é importante, mas me parece ainda incapaz de derrubar o argumento de Dworkin. Este não pode ser colocado entre esses filósofos liberais à procura de um fundamento da razão que sustente toda sua teoria - essa seria uma versão de "arquimedianismo" que Dworkin rejeita ${ }^{36}$ - mas não é isso o que faz da sua objeção não valer para Dworkin. O ponto é: ao contrário do que Williams imagina com o seu exemplo, o máximo que a história pode fazer nesse caso é colocar dúvida sobre as justificações que damos às nossas concepções de liberdade e igualdade, de modo que sejamos levados a inspecioná-las, juntamente a nossas convicções também afetadas ao nosso tempo e sociedade, com maior rigor. A história nos faz cuidadosos acerca de nossas justificações. Mas só um argumento moral melhor construído acerca do valor nomeado por esses conceitos é capaz de nos fazer rejeita-las. ${ }^{37}$

O que Williams pretendia com sua objeção utilizando o exemplo citado não era só, contudo, pontuar que a história pode desmantelar teorias que sustentem valores liberais. Daquele exemplo seguia a seguinte afirmação: teóricos liberais que justificam o liberalismo com um fundamento na razão não possuem uma "teoria do erro", uma explicação acerca do por que essas pessoas "de outros lugares" e "do passado"

\footnotetext{
${ }^{36}$ Seus argumentos contra o arquimedianismo na filosofia moral podem ser encontrados em DWORKIN, Ronald. Justice for Hedgehogs. p. 25 (assim como todo o capítulo, pp. 23-39) e p. 82-6.

37 Uma outra objeção a ser levantada contra Dworkin a partir daqui seria a de que os conceitos de valores como liberdade e igualdade são usados de forma diferente em diferentes lugares. Penso que Dworkin se atentaria à comunidade política que está interpretando: desde que haja uma "base comum" de convicções bastante abstratas a partir das quais as melhores concepções de liberdade e igualdade como valores políticos poderão ser reconstruídas, será possível falar na melhor concepção desses conceitos, a despeito do uso superficialmente parecer tão distinto. Ver DWORKIN, Ronald. Justice for Hedgehogs. p. 170-1.
} 
ABREU, Jacqueline de Souza. Conceitos de valor, interpretação, direito e política: críticas de Bernard Williams a Ronald Dworkin. Revista Eletrônica Direito e Política, Programa de Pós-Graduação Stricto Sensu em Ciência Jurídica da UNIVALI, Itajaí, v.13, n.2, $2^{\circ}$ quadrimestre de 2018. Disponível em: www.univali.br/direitoepolitica - ISSN 1980-7791

entendiam as coisas "erradamente". ${ }^{38}$ Com isso pretende dizer, como deixa claro em outros textos ${ }^{39}$, que a história seria capaz de mostrar que conceitos morais, políticos e éticos não podem ser considerados como "corretos" ou "melhores", como na acepção de Dworkin. ${ }^{40}$

Williams sempre utiliza esse argumento contrapondo-o ao que ocorre na ciência. ${ }^{41}$ Nessa área, segundo ele, ao contrário do que ocorre na moral, é possível se compreender por que pessoas no passado pensavam ou pessoas de outros lugares pensam de forma diferente, errada, por que as teorias avançadas em ciência são capazes de ser "justificatórias":

A teoria posterior, ou a visão mais geral, faz sentido de si mesma, e da visão anterior, e da transição da anterior para a posterior, em termos que ambas as partes (os defensores da visão antiga, e os defensores da visão posterior) tenham razão para reconhecer a transição como um aperfeiçoamento. Eu chamarei a explicação que satisfaz essa condição de justificatória [vindicatory]. ${ }^{42}$

Não é difícil entender o ponto de Williams quando se lembra que a física quântica mostrou as insuficiências da física newtoniana e um "aperfeiçoamento" foi reconhecido pela comunidade científica desse ramo. A história de conceitos

\footnotetext{
38 Ver WILLIAMS, Bernard. In the beginning was the deed. Editado por Geoffrey Hawthorn. Princeton and Oxford: Princeton University Press, 2005, p. 11; 66-7. Também a introdução de Geoffrey Hawthorn a esse livro de Williams, na p. xiii.
}

39 WILLIAMS, Bernard. Philosophy as a humanistic discipline. Princeton and Oxford: Princeton University Press, 2006, p. 189-91.

40 Existe uma divergência que está ao fundo desta crítica que diz respeito ao questionamento dos limites do próprio conceito de razão moral e de racionalidade para Williams e para Dworkin, o que constituiria um objeto autônomo de investigação, uma vez que envolve entender o que é verdade e objetividade para ambos. Nas próximas linhas, faço breves apontamentos que me permitem um posicionamento sobre esta crítica. Reconheço aqui, desde já, que o tema mereceria pesquisa própria.

${ }^{41}$ Ver WILLIAMS, Bernard. In the beginning was the deed. p. 66; WILLIAMS, Bernard. Philosophy as a humanistic discipline. p. 189-91; WILLIAMS, Bernard. Essays and Reviews: 1959-2002. p. 410.

42 WILLIAMS, Bernard. Essays and Reviews: 1959-2002. p. 189, tradução minha. 
ABREU, Jacqueline de Souza. Conceitos de valor, interpretação, direito e política: críticas de Bernard Williams a Ronald Dworkin. Revista Eletrônica Direito e Política, Programa de Pós-Graduação Stricto Sensu em Ciência Jurídica da UNIVALI, Itajaí, v.13, n.2, $2^{\circ}$ quadrimestre de 2018. Disponível em: www.univali.br/direitoepolitica - ISSN 1980-7791

científicos, como o que se entende por "átomo", por exemplo, é justificatória (vindicatory) das concepções que temos hoje. A história de conceitos políticos e éticos, como são o caso de liberdade e igualdade, por outro lado, não é capaz de justificar (vindicate) as concepções que temos hoje (ou a de outros lugares), porque não há reconhecimento das "duas partes" de que houve "aperfeiçoamento" desses conceitos. Para que se pudesse dizer que a noção de igualdade liberal (e de direitos iguais) é correta - Williams fala em "vencer o argumento" nesse caso - em detrimento do que era igualdade no Antigo Regime,

os representantes do Antigo Regime teriam que ter compartilhado com liberais nascentes uma concepção daquilo sobre o que era o argumento, e não simplesmente no sentido de que era sobre a forma como viver ou a forma como ordenar a sociedade. Eles teriam de ter concordado que havia um objetivo, de razão ou liberdade ou qualquer coisa, ao qual as ideias liberais melhor serviam ou do qual elas eram uma expressão melhor, e não há tanta razão, com uma mudança tão radical como essa, para pensar que eles realmente concordaram sobre isso, pelo menos até muito tempo depois nesse processo. ${ }^{43}$

A meu ver, neste trecho, Williams faz a exigência de que membros do Antigo Regime e insurgentes liberais estivessem de acordo sobre um mesmo critério do que seria igualdade, para que aqueles que defendiam antigas concepções de igualdade fossem capazes de reconhecer que igualdade é o que liberais dizem que é - e que estes possam falar que absolutistas estavam "errados". A contraposição que ele faz entre conceitos científicos e conceitos éticos e políticos é ainda sintomática de um ceticismo que pretende que a mesma teoria da verdade cabível à ciência seja estendida à moral em termos gerais.

Isso nos leva à crítica de Dworkin a Isaiah Berlin, segundo a qual este ignorava a distinta "gramática" dos conceitos de liberdade e igualdade na argumentação político-

43 WILLIAMS, Bernard. Philosophy as a humanistic discipline. p. 190, tradução minha. 
ABREU, Jacqueline de Souza. Conceitos de valor, interpretação, direito e política: críticas de Bernard Williams a Ronald Dworkin. Revista Eletrônica Direito e Política, Programa de Pós-Graduação Stricto Sensu em Ciência Jurídica da UNIVALI, Itajaí, v.13, n.2, $2^{\circ}$ quadrimestre de 2018. Disponível em: www.univali.br/direitoepolitica - ISSN 1980-7791

moral: o seu funcionamento como conceitos interpretativos. ${ }^{44}$ É claro que um historiador das ideias ou um sociólogo são capazes de elaborar definições acerca do que constituía igualdade no Antigo Regime e de como essa noção ganhou novos moldes com a Revolução Francesa, dizendo que houve bastante desacordo e disputa durante a "transição", e que os argumentos liberais "venceram". O ponto, contudo, é que não é esse o exercício que interessa ao filósofo político que pretende defender concepções de liberdade e igualdade que melhor revelem nossos compromissos com esses conceitos e as exigências que decorrem deles acerca de como um Estado deve ser arquitetado e do que ele deve proteger. Em disputas que envolvem conceitos de valores, o uso que se faz dos mesmos é interpretativo, não criterial (como parece ter suposto Williams ${ }^{45}$ neste trecho). Há disputas justamente porque não se compartilham critérios e exigir que critérios sejam compartilhados para se poder dizer qual é a concepção correta do conceito ou a aplicação correta dele é negligenciar o modo de uso de tais conceitos.

Sendo eles conceitos interpretativos, a teoria da verdade aplicável a eles é também distinta daquela que mais amplamente se defende na ciência. A física clássica mostrou-se ultrapassada quando deixou de explicar fenômenos mais complexos, e, nesse sentido, deixou de se mostrar "correta" porque não correspondia à realidade, o que se conclui a partir de experimentos. Por isso toda a comunidade científica assim o reconheceu. O que é "correto" na interpretação de conceitos de valores, por outro lado, não pode ser o que corresponde à realidade enquanto fato bruto, mas sim o

\footnotetext{
${ }^{44}$ DWORKIN, Ronald. Do liberal values conflict?; DWORKIN, Ronald. Do Values Conflict? A hedgehog's approach.

45 Em DWORKIN, Ronald. Justice for Hedgehogs p. 350, Dworkin sugere o seguinte acerca da abordagem de Williams que defende a necessidade da história para a análise de conceitos desse tipo: "Perhaps those philosophers [Berlin e Williams] who believe that a study of these concepts must be densely historical have simply assumed that the concepts are criterial."
} 
ABREU, Jacqueline de Souza. Conceitos de valor, interpretação, direito e política: críticas de Bernard Williams a Ronald Dworkin. Revista Eletrônica Direito e Política, Programa de Pós-Graduação Stricto Sensu em Ciência Jurídica da UNIVALI, Itajaí, v.13, n.2, $2^{\circ}$ quadrimestre de 2018. Disponível em: www.univali.br/direitoepolitica - ISSN 1980-7791

argumento mais bem-sucedido que pode ser construído acerca de determinado conceito. ${ }^{46}$

\section{UM MODELO DE DECISÃO BASEADO NO DIREITO CONSTITUCIONAL?}

Williams também afirma em Liberalism and Loss que Dworkin aplica um modelo de interpretação típica de decisões constitucionais para decisões políticas ${ }^{47}$ do Estado em casos que envolvem valores como liberdade e igualdade. ${ }^{48}$ Isso porque "decisões de direito constitucional são entendidas de tal forma que, primeiro, se o caso é corretamente [right/y] decidido, ninguém terá sido injustiçado [wronged]; e, segundo, a única reclamação sobre a decisão que poderia carregar peso ético real e último seria aquela de que alguém foi injustiçado [wronged]". ${ }^{49}$ Esteja esta visão certa ou não sobre o direito constitucional, o ponto é que, segundo Williams, é um erro fundamental supor que decisões políticas são algo parecido com isso. ${ }^{50}$ Oponentes políticos que disputam que concepções de valores como liberdade e igualdade devem ser perseguidos não estão interpretando um mesmo texto só ${ }^{51}$, uma constituição.

O que Williams parece querer dizer com isso é que pessoas com diferentes opiniões políticas não estão partindo de uma mesma base compartilhada (direção contrária do que argumenta Dworkin), a que recebe interpretação e com que essa interpretação

\footnotetext{
${ }^{46}$ Sobre a verdade na ciência e na interpretação, ver DWORKIN, Ronald. Justice for Hedgehogs $p$. 157-188.

47 Sobre o sentido de decisões políticas em Williams: "A very important reason for thinking in terms of the political is that a political decision - the conclusion of a political deliberation which brings all sorts of considerations, considerations of principle along with others, to one focus of decision - is that such a decision does not in itself announce that the party was morally wrong or, indeed, wrong at all. What it immediately announces is that they have lost". (WILLIAMS, 2005, p. 13)
}

${ }^{48}$ WILLIAMS, Bernard. Liberalism and Loss. p. 97-9; WILLIAMS, Bernard. In the beginning was the deed. p. $86 ; 126-7$.

49 WILLIAMS, Bernard. Liberalism and Loss. p. 98, tradução minha.

50 WILLIAMS, Bernard. Liberalism and Loss. p. 99.

${ }^{51}$ WILLIAMS, Bernard. In the beginning was the deed. p. $12,78,86$. 
ABREU, Jacqueline de Souza. Conceitos de valor, interpretação, direito e política: críticas de Bernard Williams a Ronald Dworkin. Revista Eletrônica Direito e Política, Programa de Pós-Graduação Stricto Sensu em Ciência Jurídica da UNIVALI, Itajaí, v.13, n.2, $2^{\circ}$ quadrimestre de 2018. Disponível em: www.univali.br/direitoepolitica - ISSN 1980-7791

deve se adequar, fixando seus limites. Elas possuem diferentes visões do que são igualdade e liberdade, por exemplo, e a forma como reagem a situações que impõem conflitos entre liberdade e igualdade está relacionada com essas visões. Elas ainda reclamam sobre o que é decidido em tais situações, mesmo que não considerem que tenham sido injustiçadas [wronged], pois possuem diferentes concepções desses valores. Há outras reclamações, as fundadas nessas visões distintas, e isto é típico da disputa política. Uma pessoa pode muito bem achar que a decisão política errada foi tomada, porque não compartilha a concepção de igualdade que ela pretende realizar, mas concordar com o processo (legislativo democrático) que decidiu, ou seja, admitindo que não foi injustiçada (wronged). Este é o caso do "paradoxo da democracia". Isto não significa, contudo, que não possa continuar reclamando da decisão tomada e se mobilizar politicamente para promover alterações. É o que políticos fazem.

O argumento central de Williams em From freedom to liberty segue uma estratégia um pouco distinta para fazer essa crítica. Nesse artigo, Williams afirma que o "defeito filosófico" de Dworkin é "basear a ideia de liberdade [liberty] naquela de um apelo legítimo de liberdade [rightful claim in liberty]"52, ou seja, seu erro seria igualar liberdade com direitos a liberdades, violação da liberdade com violação de direitos. É um defeito porque "a ideia de um 'apelo legítimo de liberdade' implica uma concepção jurídica de uma autoridade com a qual se concorda que pode por direito [rightfully] deferir ou rejeitar um tal apelo"53. Isto é, assim entendo: falar em liberdade como direitos supõe que uma autoridade possa determinar o que é e quando há liberdade. O problema é que "oponentes políticos não necessariamente entendem a sua situação nesses termos" 54 . Como assim?

\footnotetext{
52 WILLIAMS, Bernard. In the beginning was the deed. p. 86, tradução minha.

53 WILLIAMS, Bernard. In the beginning was the deed. p. 86, tradução minha.

54 WILLIAMS, Bernard. In the beginning was the deed. p. 86, tradução minha.
} 
Primeiro, há oponentes de diferentes sistemas políticos que podem não concordar quanto à autoridade que legitima suas decisões para eles. ${ }^{55}$ Ou seja, pessoas de diferentes comunidades não estão de acordo sobre quem tem autoridade para dizer quando se deve atender a um apelo de liberdade, porque correto. Segundo, entre oponentes políticos de um mesmo político (polity), o que fazem é concordar sobre a autoridade ou processo que determina o que vai acontecer, o que é diferente de concordar com a decisão de uma autoridade sobre o que é legítimo em um apelo de liberdade. ${ }^{56}$ Ou seja, mesmo em uma comunidade política como a brasileira, em que as pessoas estão de acordo com o processo legislativo que determina as leis decisões políticas - a se tornarem vinculantes, concorda-se com o processo, mas não com o resultado legislativo dele em termos do que diz sobre quais direitos as pessoas têm corretamente. Várias razões afetam uma decisão política sobre o que vai acontecer e que pode afetar a liberdade (liberty) das pessoas de várias maneiras, não sendo essa decisão um anúncio do que é um apelo legítimo de liberdade (Williams, 2005, p. 86). ${ }^{57}$ Este ponto de Williams é bastante forte enquanto se volta à realidade.

É verdade que, nos sistemas políticos em que há revisão judicial ou controle de constitucionalidade (judicial review), as decisões políticas tomadas pelo legislativo e pelo executivo podem ser controladas em face de apelos de liberdade, assume Williams (2005, p. 86). ${ }^{58}$ Nesses lugares, caso de várias democracias contemporâneas, parece que a liberdade que temos será mesmo o que uma autoridade diz que é. A "correção" do apelo é controlada por um tribunal constitucional, que verificará se é fundado em direito (se é rightful, para usar o vocabulário até aqui) ou não. Ao tratar deste assunto, Williams parece querer encontrar uma razão por que uma visão como a de Dworkin, em que a liberdade que

\footnotetext{
${ }^{55}$ WILLIAMS, Bernard. In the beginning was the deed. p. 86.

${ }^{56}$ WILLIAMS, Bernard. In the beginning was the deed. p. 86.

57 WILLIAMS, Bernard. In the beginning was the deed. p. 86.

58 WILLIAMS, Bernard. In the beginning was the deed. p. 86.
} 
ABREU, Jacqueline de Souza. Conceitos de valor, interpretação, direito e política: críticas de Bernard Williams a Ronald Dworkin. Revista Eletrônica Direito e Política, Programa de Pós-Graduação Stricto Sensu em Ciência Jurídica da UNIVALI, Itajaí, v.13, n.2, $2^{\circ}$ quadrimestre de 2018. Disponível em: www.univali.br/direitoepolitica - ISSN 1980-7791

as pessoas têm é a liberdade correta enquanto direito, pareceria ter algum fundamento. "Em tal estado, algumas decisões políticas, em sentido largo, são decisões judiciais: i.e., a decisão que decide o que vai acontecer é feita por razões judiciais". ${ }^{59} \mathrm{O}$ erro de Dworkin persiste:

Mas mesmo aqui o sentido de que a liberdade [liberty] de alguém é restringida por uma decisão não pode ser identificado com o pensamento de que o tribunal, se agiu corretamente [right/y], iria deferir ou teria deferido ou mesmo deveria ter deferido o apelo de liberdade de alguém. Alguém pode concordar que o tribunal, se estava fazendo seu trabalho apropriadamente, não teria deferido tal apelo, mas alguém ainda pode sentir que a decisão restringe ou mesmo viola sua liberdade. Primeiro, o próprio tribunal pode aceitar que sua decisão, apesar de correta, envolve um custo de liberdade. ${ }^{60}$ Uma razão mais geral, entretanto, é que razões judiciais, o tipo de razões a que um tribunal constitucional, não importa quão inventivas, deve atender, são só um tipo de razão. (Mesmo aqueles como Dworkin que pensam que revisão judicial deveria incluir expressa e extensamente razões morais aceitam que, uma vez que essas são decisões dentro de um sistema jurídico, elas estão vinculadas a certos constrangimentos, como a stare decidis.) Então a pessoa que sente que sua liberdade foi ferida pode sentir isso por causa de outras razões, mesmo razões de princípio, que ele não supõe que justificariam um apelo de direito no fórum judicial. ${ }^{61}$

Assim, alguém pode concordar com o que um tribunal decide sobre qual liberdade ela tem, mas discordar com a decisão por outras razões. Não é difícil compreender o

59 WILLIAMS, Bernard. In the beginning was the deed. p. 86, tradução minha.

60 Williams não parece errado em supor que tribunais sustentam o que consideram ser decisões corretas mesmo reconhecendo um custo de liberdade. O voto do Ministro Gilmar Mendes no caso Ellwanger apreciado pelo Supremo Tribunal Federal (HC 82.424-RS, julgado 17 de set. 2003), por exemplo, sugere isto: a liberdade de expressão precisava ser de alguma forma sacrificada pela igualdade. E isso era o correto a fazer naquele caso. Casos em que os juízes se engajam em "sopesamento de princípios" como método para se chegar a uma decisão correta, mas que importará algum custo para um ou todos eles, de modo geral, sustentam essa assunção de Williams. (Ele cita o caso Panned Parenthood v. Casey 505 US 833 (1992), em que a Suprema Corte americana teria se engajado em 'balancing' neste trecho.) Adiante teremos de investigar quais razões Dworkin teria para contraditá-la.

61 WILLIAMS, Bernard. In the beginning was the deed. p. 86-7, tradução minha. 
ABREU, Jacqueline de Souza. Conceitos de valor, interpretação, direito e política: críticas de Bernard Williams a Ronald Dworkin. Revista Eletrônica Direito e Política, Programa de Pós-Graduação Stricto Sensu em Ciência Jurídica da UNIVALI, Itajaí, v.13, n.2, $2^{\circ}$ quadrimestre de 2018. Disponível em: www.univali.br/direitoepolitica - ISSN 1980-7791

ponto aqui, a partir de um exemplo: uma pessoa pode concordar com o Supremo Tribunal Federal (STF) no sentido de que, segundo a Constituição brasileira, a legislação eleitoral antes em vigor fere a igualdade protegida constitucionalmente, e por isso a liberdade de doar deve ser (ainda mais) restringida, mas acreditar, por razões outras, talvez por endossar alguma versão do libertarismo, que esta decisão restringe sua liberdade. Assim, mesmo em Estados com instituições que realizam judicial review, as pessoas não entendem que a liberdade que elas têm seja o que uma autoridade diz que elas têm por direito, legitimamente. Concordar-se com a autoridade do STF para decidir, mas não com as determinações que faz, ainda que concordem que devam ser respeitadas.

O argumento de Williams é, portanto, o seguinte: a ideia de que uma ação, como ocorre em uma decisão política, envolve um custo na liberdade (cost in liberty) de alguém não necessariamente envolve a ideia de que alguém teria um apelo legítimo de liberdade - um apelo fundado em direito - diante de uma autoridade. ${ }^{62} \mathrm{O}$ erro de Dworkin seria igualar situações em que há violação da liberdade com casos em que há violação a um direito oponível judicialmente.

Não acredito que Dworkin cometa esse erro. Ele não supõe que a concepção correta de liberdade ou de igualdade seja aquela que uma autoridade diz que é. Há violação na liberdade e na igualdade, para esse autor, quando o que valorizamos é atingido. Em todos os outros casos, não há nada de valor que se perde. Por isso ele fala que só podemos tirar essas conclusões a partir das melhores concepções desses valores. Só podemos saber se há violação se oferecermos uma justificativa adequada à reconstrução do apelo valorativo de nossas práticas e convicções e dela pudermos concluir que algo de valor foi indevidamente afetado. Isso vale tanto para decisões judiciais quanto políticas.

Em se tratando de um caso em que pareça que a igualdade restrinja a liberdade, mas

62 WILLIAMS, Bernard. In the beginning was the deed. p. 87. 
ABREU, Jacqueline de Souza. Conceitos de valor, interpretação, direito e política: críticas de Bernard Williams a Ronald Dworkin. Revista Eletrônica Direito e Política, Programa de Pós-Graduação Stricto Sensu em Ciência Jurídica da UNIVALI, Itajaí, v.13, n.2, $2^{\circ}$ quadrimestre de 2018. Disponível em: www.univali.br/direitoepolitica - ISSN 1980-7791

que seja decidido a partir de concepções como as defendidas por Dworkin, não há violação ou restrição, "injustiça" (wrong) com ninguém. Tal tragédia haveria se a realização da melhor concepção de igualdade, ou seja, da igualdade de recursos, orientasse medidas que infringissem a melhor concepção de liberdade, os direitos em sentido forte a determinadas liberdades. Não é esse o caso, segundo Dworkin. ${ }^{63}$ Uma decisão só envolve mesmo um custo em liberdade, como valor político, se ela inapropriadamente violar um direito moral forte à liberdade. Se for este o caso, essa decisão poderá ser criticada pela sua incorreção.

A liberdade como direitos em sentido forte enquanto a melhor concepção de liberdade defendida por Dworkin não necessariamente coincide com os direitos positivados em uma Constituição, ao contrário do que Williams parece supor em sua crítica a Dworkin. Ela poderá ser criticada, assim como também as decisões judiciais que dela decorrerem. Se houver convicções e paradigmas de liberdade nessa sociedade que sustentem a constitucionalização de outros direitos, ou de uma interpretação distinta daquela que eles vêm recebido, o Estado ou o tribunal constitucional poderão ser criticados por errar dessa forma.

A crítica que existe nesse caso, contudo, não é porque, mesmo que a decisão tenha respeitado o "direito constitucional"64, permanece um ressentimento. A crítica se dá em razão de o direito constitucional ou a interpretação que é dada a ele se afastarem da melhor concepção de liberdade ou de igualdade enquanto valores políticos. Essa concepção não está circunscrita em uma comunidade política à narrativa do texto constitucional ou ao que uma autoridade diz que é: a "base compartilhada" que

\footnotetext{
${ }^{63}$ DWORKIN, Ronald. Sovereign Virtue: The Theory and Practice of Equality.
}

64 Dworkin reconhece que "o direito é diferente" (ver DWORKIN, Ronald. Justice for Hedgehogs. p. 171). Como Williams aponta em seu comentário, a stare decisis pode afetar aquilo que é a decisão correta juridicamente em algum caso envolvendo virtudes políticas: "any plausible conceptions of law and justice must suppose that local decisions have a force in fixing what law requires that they do not have in fixing what is just or unjust". Isso não muda o ponto que se pretende fazer aqui. Falar que só há violação da liberdade quando a correta concepção de liberdade é atingida não vale só para o direito e nem depende do que uma autoridade diz. 
ABREU, Jacqueline de Souza. Conceitos de valor, interpretação, direito e política: críticas de Bernard Williams a Ronald Dworkin. Revista Eletrônica Direito e Política, Programa de Pós-Graduação Stricto Sensu em Ciência Jurídica da UNIVALI, Itajaí, v.13, n.2, $2^{\circ}$ quadrimestre de 2018. Disponível em: www.univali.br/direitoepolitica - ISSN 1980-7791

precisamos para poder dizer que sustentamos a interpretação correta acerca do que são liberdade e igualdade são as nossas próprias convicções mais abstratas sobre a forma como o Estado deve nos tratar para ser legítimo. Essa atitude interpretativa está presente em esferas em que se lança mão de argumentos político-morais, seja no direito ou na política.

\section{CONSIDERAÇÕES FINAIS}

Neste artigo, explorei dois argumentos de Williams contra Dworkin e defendi este das críticas daquele. Sobre a acusação de que não dá a devida atenção à história na análise dos conceitos de valores, argumentei que a história pode ser capaz de explicar origens de concepções rivais de liberdade e igualdade, mas não faz parte das justificações delas, que é a dimensão que importa para verificar se há conflito entre tais valores políticos. Quanto à afirmação de que Dworkin estaria tentando impor um modelo de interpretação constitucional a valores políticos, defendi que as concepções corretas de liberdade e igualdade, as que mostram o seu valor, não estão circunscritas àquilo que autoridades judiciais ou políticas dizem que são, mas às melhores reconstruções desses valores. Diante disso, conclui que a visão de Dworkin sobre a inexistência de conflito inevitável entre valores sobrevive às críticas de Williams.

Com este projeto, pretendi examinar aspectos centrais do pensamento de Ronald Dworkin, a partir das críticas sofisticadas de um filósofo igualmente fascinante, ainda pouco estudado no Brasil: Bernard Williams. Apesar de ter defendido Dworkin das críticas de Williams, penso que o trabalho mostrou que os autores divergem em questões metodológicas centrais, em especial sobre como conceitos de valores devem ser analisados e qual a relação entre o direito e a política, divergência que merece uma atenção cada vez maior da academia. ${ }^{65}$

\footnotetext{
${ }^{65}$ Agradeço à Fundação de Amparo à Pesquisa do Estado de São Paulo pela bolsa de pesquisa que me permitiu estudar o debate entre Ronald Dworkin e Bernard Williams e também ao professor Ronaldo Macedo pelo apoio, incentivo e orientação.
} 


\section{REFERÊNCIAS DAS FONTES CITADAS}

ABREU, Jacqueline de Souza. O pluralismo de valores e sua importância política na obra de Bernard Williams. Teoria Jurídica Contemporânea, vol. 2, n.1, p. 6-38.

BERLIN, Isaiah. The hedgehog and the fox. London: Weidenfeld \& Nicolson, 1953. CALCUTT, Daniel (ed.). Reading Bernard Williams. New York: Routledge, 2009.

DWORKIN, Ronald; LILLA, Mark; SILVERS, Robert (eds.). The Legacy of Isaiah Berlin. New York: The New York Review of Books, 2001.

DWORKIN, Ronald. Do liberal values conflict?. In: R. DWORKIN; M. LILLA; R. SILVERS. The Legacy of Isaiah Berlin. New York: The New York Review of Books, p. 91-104, 2001a.

DWORKIN, Ronald. Do liberty and equality conflict?. In: P. BARKER (ed.). Living as equals. Oxford, Oxford University Press, p. 39-57, 1996.

DWORKIN, Ronald. Do Values Conflict? A hedgehog's approach. Arizona Law Review, vol. 43, pp. 251-259, 2001b.

DWORKIN, Ronald. Justice for Hedgehogs. Cambridge, MA: Harvard University Press, 2011.

DWORKIN, Ronald. Law's Empire. Cambridge, MA: Harvard University Press, 1986.

DWORKIN, Ronald. 0 império do direito. $2^{\mathrm{a}}$ Ed. São Paulo: Martins Fontes, 2007.

DWORKIN, Ronald. Sovereign Virtue: The Theory and Practice of Equality. Cambridge, MA: Harvard University Press, 2000.

DWORKIN, Ronald. Uma questão de princípio. $2^{\mathrm{a}}$ Ed. São Paulo: Martins Fontes, 2005.

HALL, Edward. Realism and Liberalism in the Political Thought of Bernard Williams. Tese de Doutorado submetida ao Department of Government da London School of Economics and Political Science. 269 p. 2013. Disponível em: http://etheses.Ise.ac.uk/881/ . Acesso: 07.09.2017.

JENKINS, Mark. Bernard Williams. Chesham: Acumen, 2006.

KOOPMAN, Colin. Bernard Williams on Pluralism, Liberalism, and History. Theoretical and Applied Ethics, vol. 3, n.1, pp. 11-21, 2011.

MACEDO JUNIOR, Ronaldo P. Do xadrez à cortesia: Dworkin e a Teoria do Direito Contemporânea. São Paulo: Saraiva, 2013. 
ABREU, Jacqueline de Souza. Conceitos de valor, interpretação, direito e política: críticas de Bernard Williams a Ronald Dworkin. Revista Eletrônica Direito e Política, Programa de Pós-Graduação Stricto Sensu em Ciência Jurídica da UNIVALI, Itajaí, v.13, n.2, $2^{\circ}$ quadrimestre de 2018. Disponível em: www.univali.br/direitoepolitica - ISSN 1980-7791

THOMAS, Alan (ed.). Bernard Williams. Cambridge: Cambridge University Press, 2007.

WALLUCHOW, W.; SCIARAFFA, S. (ed.). The Legacy of Ronald Dworkin. Oxford, Oxford University Press, 2016.

WILLIAMS, Bernard. Essays and Reviews: 1959-2002. Princeton: Princeton University Press, 2014.

WILLIAMS, Bernard. In the beginning was the deed. Editado por Geoffrey Hawthorn. Princeton and Oxford: Princeton University Press, 2005.

WILLIAMS, Bernard. Liberalism and Loss. In: DWORKIN, Ronald; LILLA, Mark; SILVERS, Robert. The Legacy of Isaiah Berlin. New York, The New York Review of Books, p. 91-104, 2001a.

WILLIAMS, Bernard. Philosophy as a humanistic discipline. Princeton and Oxford: Princeton University Press, 2006.

Recebido em: 05/05/2018

Aprovado em: 21/07/2018 